\title{
PELATIHAN PEMBUATAN BLOG PADA SISWA LEMBAGA KURSUS PENDIDIKAN (LKP) MANDIRI
}

\author{
Jeperson Hutahaean", Zulfi Azhar, Yessica Siagian, Arridha Zikra Syah \\ Sistem Informasi, STMIK Royal Kisaran \\ email: jepersonhutahean@gmail.com
}

\begin{abstract}
The Mandiri Computer Education Course (LKP) Institute, Asahan, North Sumatra, is a training institution that provides Information Technology training packages. During this time the training carried out by tutors only featured internet or existing people's blogs without teaching them to create blogs. Then the Community Service Team (PKM) STMIK Royal Kisaran providing training to students of the LKP as an addition to the deepening of blog material that is felt necessary to be given to students LKP. Implementation is done by direct practice accompanied by presentations and discussions and using computers to provide direct understanding to students LKP. The material of activities given to participants can be used and used directly by students in creating a blog in accordance with the concepts that exist in creating a blog.
\end{abstract}

Keywords: Blogs, Computers, Institutions Educational Courses, Training, Students

\begin{abstract}
Abstrak: Lembaga Kursus Pendidikan (LKP) Mandiri Komputer Kabupaten Asahan Sumatera Utara, merupakan lembaga pelatihan yang menyediakan paket-paket pelatihan Teknologi Informasi. Selama ini pelatihan yang dilaksanakan oleh tutor hanya menampilkan internet atau blog orang yang sudah ada tanpa mengajarinya dalam pembuatan blog. Maka tim Pengabdian kepada masyarakat (PKM) STMIK Royal Kisaran memberikan pelatihan kepada siswa LKP tersebut sebagai penambahan pendalaman materi blog yang dirasakan perlu untuk diberikan kepada siswa LKP. Pelaksanaan dilakukan dengan cara praktek langsung disertai dengan presentasi dan diskusi dan menggunakan komputer untuk memberikan pemahaman langsung kepada siswa LKP. Materi kegiatan yang diberikan kepada peserta dapat digunakan dan dimanfaatkan langsung oleh siswa dalam membuat blog sesuai dengan konsep yang ada pada pembuatan blog.
\end{abstract}

Kata kunci: Blog, Komputer, Lembaga Kursus Pendidikan, Pelatihan, Siswa

\section{PENDAHULUAN}

Lembaga Kursus Pendidikan (LKP) Mandiri Komputer Kabupaten Asahan Sumatera Utara, merupakan lembaga pelatihan yang menyediakan paket-paket pelatihan Teknologi
Informasi dengan standar sebagai User termasuk didalamnya Paket Web Desain. Paket tersebut merupakan pelatihan yang menggunakan Mozila firefox, internet explorer dan opera sebagai aplikasinya. Berbagai pelatihan disediakan oleh tutor di 
Jurdimas (Jurnal Pengabdian Kepada Masyarakat) Royal

Vol. 2 No. 1, Jan 2019, hlm. 65 - 74

ISSN 2614-7912 (Print)

DOI: https://doi.org/10.33330/jurdimas.v2i1.28

ISSN 2622-3813 (Online)

Available online at https://jurnal.stmikroyal.ac.id/index.php/jurdimas

sana, seperti penggunaan internet.

Selama ini pelatihan yang

dilaksanakan oleh tutor hanya menampilkan internet atau blog orang yang sudah ada tanpa mengajarinya dalam pembuatan blog. Sementara supaya anak didik bertambah pintar dan menambah ilmu pengetahuan serta wawasan lebih dari itu, materi pelatihan yang diberikan juga tidak terlalu dalam. Materi hanya mengenal blog saja saja tanpa belajr mebuatnya. Untuk itu, penambahan pendalaman materi dirasakan perlu untuk diberikan kepada tutor ataupun peserta. Hal tersebut juga digunakan sebagai parameter keahlian yang dimiliki oleh tim pengabdian kepada masyarat.

\section{METODE}

Tahapan atau langkah-langkah yang ditempuh agar terlaksana dengan baik dan lancar serta tercapainya tujuan kegiatan pengabdian kepada masyarakat ini adalah:

1. Mempersiapkan materi yang akan diberikan, baik modul, slide presentasi, dan alat peraga lainnya.

2. Memastikan tempat dan fasilitas pendukung seperti infocus, projector, dan lain-lain sudah standby pada saat kegiatan akan dilangsungkan.

3. Sebelum kegiatan dilakukan peserta yang mengikuti kegiatan ini harus sudah memiliki komputer atau laptop sebagai alat praktek.

4. Menjelaskan teori tentang materi aplikasi yang digunakan

5. Paktek langsung pada komputer atau laptop dalam mengimplementasikan blog

6. Membahas kasus yang berkaitan dengan blog.
7. Diskusi dan tanya jawab.

8. Dalam kegiatan ini kepala desa menyediakan tempat selama kegiatan dilangsungkan dan fasilitas-fasilas penunjang yang mereka punya untuk mendukung kegiatan ini berjalan dengan baik dan lancar.

Setelah kegiatan pengabdian kepada masyarakat ini dilakukan, maka langkah selanjutnya adalah Tim pengabdian kepada masyarakat melakukan monitoring selama 3 sampai 4 kali pada Lembaga Kursus Komputer Mandiri, untuk memastikan para totur dan siswa sudah benarbenar mengaplikasikan aplikasi tersebut secara maksimal atau masih belum. Jika belum maka Tim akan membantu mengingatkan kembali. Tinjauan ini dilakukan setiap satu kali dalam seminggu pasca kegiatan.

\section{PEMBAHASAN}

1. Materi Kegiatan

Berkaitan dengan tema kegiatan, materi-materi yang telah diajarkan dan dipraktekkan adalah sebagai berikut:

A. Pengertian Blog

Blog merupakan singkatan dari "web log" adalah bentuk aplikasi web yang terdiri dari tulisan - tulisan yang biasa disebut sebagai posting pada sebuah halaman web. Tulisan - tulisan ini seringkali dimuat dalam urutan descending berdasarkan tanggal, artinya tanggal tulisan dengan tanggal terbaru akan ditampilkan paling atas atau depan. Meskipun begitu, di control panelnya disediakan pengaturan untuk mengatur agar tidak tampil seperti itu. Blog biasanya dapat diakses oleh semua pengguna internet sesuai dengan topic dan tujuan, serta 
Available online at https://jurnal.stmikroyal.ac.id/index.php/jurdimas

minat dari si pengguna blog tersebut. Fungsi blog sangat beragam, mulai dari catatan harian, media publikasi dalam sebuah kampanye politik, sampai dengan program-program media dan perusahaan-perusahaan. Biasanya blog di-maintain oleh seorang penulis tunggal yang juga sebagai pemilik blog tersebut, sementara sebagian lainnya dikelola oleh beberapa penulis yang tergabung dalam jaringan blog tersebut.

B. Jenis-jenis Blog

- Blog politik : Blog yang berisi informasi tentang politik, baik profil, kampanye politik,maupun propaganda politik.

- Blog pribadi; Blog milik perorangan yang biasanya memuat artikel sesuai dengan minat dan hobi si pemilik blog.

- Blog bertopik: Blog yang dikhususkan membahas tentang topic tertentu,misalnya membahas tentang fotgrafi, bisnis online, pemrograman, dan lain-lain.

- Blog kesehatan: Blog yang membahas tentang informasi seputar kesehatan.

- Blog sastra: Blog yang berisi artikel-artikel berbau sastra dan seni, baik yang bersifat lokal, regional, nasional, maupun internasional.

- Blog perjalanan: Blog yang membahas tentang informasi pariwisata bagi para pehobi travelling.

Blog Service

Blog service adalah website yang melayani pembuatan blog, layaknya sebuah perusahaan jasa penyedia email seperti Yahoo, Google, dan lain-lain. Mereka menyediakan script gratis untuk kita beraktivitas di blog. Sebagai contoh website yang menyediakan jasa layanan blog gratis adalah :

- WordPress (www.wordpress.com)

- Blogspot (www.blogger.com)

- Blogsome (www.blogsome.com)

- Multiply (www.multiply.com)

D. Langkah-langkah membuat blog di Blogspot:

\section{Membuat Email}

Salah satu syarat yang harus dipenuhi dalam membuat blog adalah anda memiliki alamat email yang masih aktif atau digunakan. Jika anda belum mempunyai alamat email, silahkan daftar terlebih dahulu di gmail karena blogger adalah salah satu layanan dari Google, maka ketika mendaftar ke blogger sebaiknya gunakan email gmail. Pastikan komputer anda terkoneksi dengan internet, buka halaman gmail.com

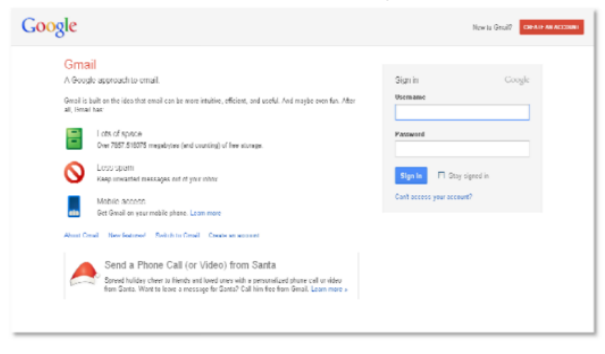

Gambar 1 Membuat akun Gmail

2. Cara membuat blog di Blogger Silahkan mengunjungi situs http://www.blogger.com

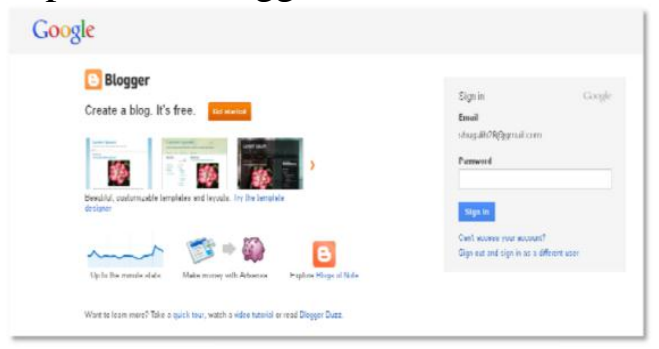

Gambar 2. Membuat Blog di Blogger 
Available online at https://jurnal.stmikroyal.ac.id/index.php/jurdimas

Anda sudah langsung masuk ke halaman Admin Blog / Dasbor. Anda dapat langsung mencoba mengisi artikel yang anda inginkan dengan mengetikkan judul dan artikel anda. Contoh tampilan pengisian / posting artikel. Klik Terbitkan entri. Dan berikut adalah tampilan dari blog anda.

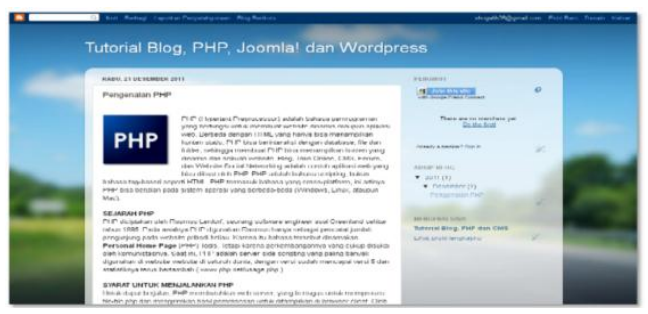

Gambar 3. Tampilan Blog di Blogger

3. Cara setting blog di Blogger

Hal pertama yang penting anda lakukan agar blog anda di blogger mempunyai performa yang baik adalah melakukan beberapa Setting atau pengaturan. Sebagai bahan inspirasi bagaimana cara melakukan setting blog di blogger, berikut Kolom Tutorial tuliskan cara pengaturan blog di blogger (pastikan anda memilih bahasa indonesia agar sesuai dengan tutorial di bawah ini:

1. Silahkan login ke Blogger dengan ID anda.

2. Klik Setelan.

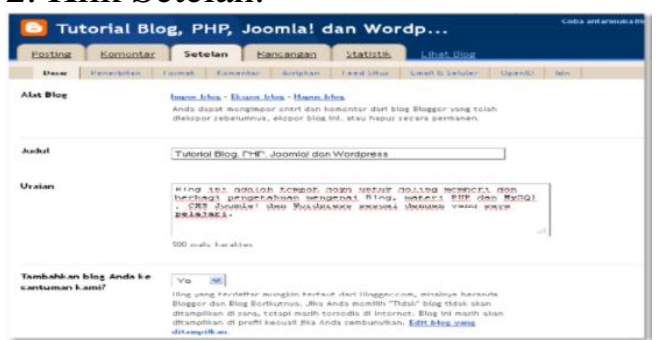

Gambar 4. Tampilan Setting Blog di Blogger

Alat Blog :

- Impor blog, ini adalah faslitas untuk mengimpor data dari komputer anda (ini biasanya dilakukan ketika transfer blog) tidak usah di klik, biarkan saja.

- Ekspor blog, ini adalah fasilitas untuk mengekspor data blog dari server blogger ke komputer anda. Fasilitas ini disebut juga sebagai fasilitas Backup blog. Disarankan agar anda membuat backup data ke komputer anda, minimal satu minggu sekali. Data backup tersebut sewaktu ketika anda ingin mentransfer ke blog lain di blogger, atau bisa juga untuk migrasi ke blog yang lain seperti Wordpress.

- Hapus blog, Fasilitas untuk menghapus blog anda. Jika anda tidak berniat untuk menghapus blog, maka jangan sekali-sekali klik link ini.makeityourring diamond engagement rings

- Judul : isi dengan judul blog yang anda inginkan. Contoh : My personal blog

- Uraian : isi dengan deskripsi blog yang ingin ditampilkan, sebaiknya ini diisi jangan dikosongkan. Contoh : Kehidupan masa kecilku.

Tambahkan blog Anda ke cantuman kami? : disarankan untuk memilih opsi Ya. Biarkan mesin pencari menemukan blog Anda? : Pilih Ya, agar blog anda dapat di index oleh mesin pencari seperti Google, Yahoo atau Bing.

Tampilkan Editing Cepat di Blog Anda? : Boleh pilih Ya atau Tidak.

Tampilkan Link Posting Email? : Ini berupa icon email, jika anda menginginkan agar pengunjung blog dengan mudah mengirimkan email ke teman mereka tentang blog anda, maka Pilih Ya. Namun jika tidak, silahkan pilih Tidak.

Konten Dewasa? : Jika blog anda nantinya akan berisi hal-hal yang 
Jurdimas (Jurnal Pengabdian Kepada Masyarakat) Royal

Vol. 2 No. 1, Jan 2019, hlm. 65 - 74

ISSN 2614-7912 (Print)

DOI: https://doi.org/10.33330/jurdimas.v2i1.28

ISSN 2622-3813 (Online)

Available online at https://jurnal.stmikroyal.ac.id/index.php/jurdimas

besifat dewasa seperti menampilkan artikel, gambar, atau video wanita seksi, dll maka pilih Ya. Namun, jika blog anda berisi hal-hal yang aman diakses oleh anak kecil, pilih Tidak. Sebagai catatan, jika anda memilih opsi Ya, maka nantinya ketika diakses blog anda akan ada peringatan bahwa berisi konten dewasa.

Pilih editor entri : Ini adalah pilihan untuk post editor. Editor yang diperbarui, ini adalah post editor terbaru yang dimiliki oleh blogger, banyak fasilitas baru yang terintegrasi dalam post editor ini seperti tombol More untuk memotong artikel di blog anda. Editor lama, ini adalah post editor lama yang dimiliki blogger namun masih bisa anda gunakan, ada beberapa toolbar terdapat dalam post editor lama, namun tidak disediakan lagi di post editor baru, jadi silahkan pilih mana yang anda mau. Sembunyikan mode penyusunan, pilihan ini khusus bagi anda yang sudah mahir dengan kode HTML, jika anda tidak menguasai tentang HTML, jangan gunakan post editor ini. Aktifkan transliterasi?: Pilih

Aktifkan jika post editor anda ingin mendukung ke translasi Hindi, Kannada, Malayalam, Tamil, atau Telugu. Pilih Nonaktifkan jika post editor anda tidak ingin ada translasi bahasa tersebut. Akhiri pengaturan menu Basic dengan klik tombol Simpan Setelan.

\section{Penerbitan}

Penerbitan merupakan fasilitas untuk mengubah nama domain anda di blogger dengan nama domain milik anda sendiri. Misal : http://namabloganda.blogspot.com menjadi http://namabloganda.com

5. Format

Beberapa pengaturan dalam menu Format :

Tampilkan sebanyak mungkin : tulis jumlah post yang ingin tampil di halaman depan blog anda. Contoh : Untuk pilihan dropdown disarankan untuk memilih opsi posting, jangan hari.

- Format Header Tanggal : Pilih format tampilan tanggal yang anda sukai

- Format Tanggal Index Arsip : pilih format tampilan arsip yang anda inginkan. Format Timestamp : Pilih format tampilan jam yang anda sukai. Jam disini adalah catatan waktu ketika artikel anda di publikasikan di blog.

- Zona Waktu : Sesuikan dengan zona waktu dimana tempat anda berada. Bahasa : Pilih bahasa yang dipakai untuk blog anda.

- Konversi ganti baris : ini adalah fasilitas line break secara otomatis ketika anda klik enter ketika membuat sebuah posting. Fasilitas ini di pakai apabila anda kedepannya tidak akan memposting tentang kode-kode semisal HTML dan lain sebagainya. Pilih Tidak, jika anda berniat nantinya akan memasukkan kode-kode HTML kedalam posting posting anda, misal jika konten blog anda berisi tutorial bahasa HTML, PHP dan lain sebagainya.

- Tampilkan Field Judul : Pilih Ya ataupun Tidak juga tidak ada masalah.

- Tampilkan kolom Link : Pilih Tidak atau Ya juga tidak ada masalah.

- Aktifkan perataan float : Pilih Ya, ini adalah agar gambar bisa diatur posisinya dalam postingan. Namun jika pilihan ini mengganggu 
Available online at https://jurnal.stmikroyal.ac.id/index.php/jurdimas

tampilan blog anda nantinya, pilih saja Tidak.

- Template Entri : ini adalah fasilitas agar isi dari Templat Entri ini akan selalu muncul pada saat membuat posting. Biasanya fasilitas ini sering di gunakan untuk signature blog, yaitu tulisan atau kode signature disimpan dalam Templat Entri, sehingga ketika anda membuat posting, kode signature tersebut akan secara otomatis muncul tanpa harus menuliskannya secara berulangulang. Akhiri Pengaturan menu Format dengan klik tombol Simpan Setelan.

\section{Komentar}

Beberapa pengaturan dalam menu komentar:

Komentar : Pilih Tampilkan, jika anda menginginkan agar postingan ada bisa di komentari oleh pengunjung. Pilih Sembunyikan, jika artikel yang anda posting tidak ingin di komentari oleh pengunjung.

- Siapa yang Bisa Berkomentar? :

Siapa pun - termasuk Pengguna Anonim, untuk pilihan ini, maka siapa saja dapat berkomentar, termasuk Pengguna Anonim atau tanpa identitas jelas. Pengguna Terdaftar - termasuk OpenID, hanya user yang teregistrasi saja yang bisa berkomentar terhadap artikel anda, yang termasuk Pengguna Terdaftar adalah mereka yang mempunya akun di Google, Live Journal, Wordpress, Type pad, AIM, serta OpenID. Pengguna dengan Google Account Yang bisa berkomentar hanyalah mereka yang mempunyai akun google.
Hanya anggota blog ini, Hanya anggota dari blog anda saja yang bisa berkomentar, ini biasanya dipakai jika blog anda adalah untuk komunitas tertentu, misal komunitas pendidikan.

- Penempatan Formulir Komentar : Halaman penuh $\square$ halaman blog anda akan di timpa oleh kotak komentar ketika ada pengunjung klik link komentar.

Jendela munculan, kotak komentar akan muncul dalam jendela baru apabila ada pengunjung yang klik link komentar Disemat di bawah entri $\square$ kotak komentar akan langsung ditampilkan langsung dibawah artikel posting anda, sehingga pengunjung dapat langsung memeberikan komentar tanpa harus klik link komentar. Format kotak komentar yang paling banyak disukai oleh blogger adalah Disemat di bawah entri.

- Default Komentar untuk Entri : pilih Entri baru memiliki komentar jika artikel post anda ingin ada kotak komentarnya, namun sewaktu-waktu anda bisa saja mematikan fungsi ini ketika melakukan posting. Pilih Entri baru tidak memiliki komentar jika artikel post anda tidak ingin mempunyai kotak komentar, namun sewaktu-waktu anda bisa saja memunculkan fungsi ini ketika melakukan posting.

- Taut balik : Pilih Tampilkan jika anda ingin menampilkan link ke website yang membuat link ke artikel yang anda buat. Pilih Sembunyikan jika anda tidak ingin menampilkan link ke website yang membuat link ke artikel yang anda buat.

- Bawaan Tautbalik untuk Posting : 
Available online at https://jurnal.stmikroyal.ac.id/index.php/jurdimas

pilih Entri baru memiliki Tautbalik jika setiap artikel yang di posting memiliki Backlinks. Pilih Entri baru tidak memiliki Taut balik jika setiap artikel yang di posting tidak ingin memiliki Backlinks.

- Format Timestamp Komentar : pilih format tampilan tanggal komentar yang anda sukai.

- Pesan Formulir Komentar : Tulis pesan yang ingin muncul diatas kotak komentar. Misal : Silahkan anda berkomentar, namun tetap jaga kesopanan dengan tidak melakukan komentar spam.

- Moderasi komentar : Pilih Selalu jika setiap komentar yang masuk ingin di moderasi terlebih dahulu oleh anda. Pilih Hanya pada entri yang lebih lawas dari jika komentar ingin di moderasi terlebih dahulu terhadapat posting yang umurnya telah anda tentukan. Pilih Tidak pernah, jika komentar yang masuk tidak ingin di moderasi terlebih dahulu dan akan langsung muncul diblog anda. Jangan lupa untuk memasukkan alamat email anda, apabila ketika ada orang yang berkomentar anda akan mengetahuinya melalui email. Atau kosongkan saja apabila anda tidak ingin menerima email pemberitahuan tentang komentar.

- Tampilkan verifikasi kata untuk komentar? : Pilih Ya jika ingin menampilkan huruf verifikasi ketika ada yang berkomentar, pilihan ini adalah untuk mencegah terhadap script robot spam yang bisa membombardir blog anda dengan komentar, walaupun begitu pilihan ini mempunyai kekurangan yaitu pengunjung blog anda biasanya malas untuk berkomentar karena merasa ribet ketika berkomentar. Pilih Ya jika tidak ingin menampilkan huruf verifikasi, pilihan ini sedikit rentan terhadap script robot spam, namun biasanya pengunjung akan lebih suka berkomentar karena mudah dilakukan.

- Tampilkan gambar profil dalam komentar? : Pilih Ya jika dalam kometar ingin ditampilkan gambar profile yang berkomentar. Pilih Tidak jika tidak ingin menampilkan gambar profile pemberi komentar.

- Email Pemberitahuan

Komentar : Masukkan alamat email yang ingin dikirim notifikasi apabila ada yang berkomentar. Jumlah maksimal email yang dapat menerima adalah 10 email. Akhiri pengaturan menu Komentar dengan klik tombol Simpan Setelan.

\section{Arsipkan}

Beberapa pengaturan dalam menu arsipkan:

- Frekuensi Arsip : pilih arsip yang ingin di tampilkan apakah Arsip tidak ada, Harian,Mingguan, atau Tiap Bulan. Disarankan untuk memilih Tiap Bulan.

- Aktifkan Halaman Posting? : Silahkan pilih Ya atau Tidak. Akhiri pengaturan menu Arsipkan dengan klik tombol Simpan Setelan.

\section{Feed Situs}

Beberapa pengaturan dalam menu Feed Situs:

- Izinkan Feed Blog : Silahkan pilih Tak satupun, Singkat, atau Penuh. Disarankan untuk memilih opsi Penuh.

- Posting URL Pengubahan Arah Feed : isi dengan alamat feed milik 
Available online at https://jurnal.stmikroyal.ac.id/index.php/jurdimas

anda, ini adalah jika anda telah melakukan burner feed seperti misalnya dengan feedburner. Namun jika belum punya, silahkan dikosongkan saja terlebih dahulu. Untuk pembahasan feed burner akan di posting pada posting selanjutnya. Post Feed Footer : Isi dengan kode yang ingin tampil pada footer post feed. Jika belum mengerti dikosongkan saja terlebih dahulu. Akhiri Pengaturan menu Feed Situs dengan klik tombol Simpan Setelan.

9. Email dan Seluler

Untuk memposting sebuah artikel kedalam blog anda, tidak hanya melalui post editor yang ada di blogger. Namun, anda pun bisa posting artikel melalui email ataupun perangkat seluler anda. Beberapa pengaturan dalam menu Email \& Seluler :

- Alamat BlogSend : tulis alamat email yang ingin dikirim notifikasi apabila anda mempublikasikan sebuah artikel. Maksimal jumlah yang bisa di kirim adalah sampai 10 buah email, format penulisan email di pisahkan dengan tanda koma (, ).

- Alamat Pengeposan via Email : buatlah alamat email blogger untuk mengirimkan posting dari email atau perangkat seluler dengan cara menuliskan pada kotak yang tersedia. Misalkan alamat email anda adalah contohsaja@gmail.com maka anda bisa membuat email blogger menjadi

contohsaja.post@blogger.com atau contohsaja.blog@blogger.com atau apa saja menurut anda yang bagus. Tapi ingat, rahasiakan alamat email ini agar orang lain tidak bisa posting ke blog anda. Alamat pengeposan via email : Untuk mengaktifkan fitur ini, anda harus memilih opsi Publikasikan segera email, artinya apabila anda mengirimkan email ke alamat diatas, isinya akan langsung diposting ke blog. Jika opsi yang dipilih adalah Simpan email sebagai entri konsep, maka email yang dikirimkan tidak akan langsung dipublikasikan, melainkan akan masuk ke post konsep.

Namun, apabila anda tidak ingin mempublikasikan melalui email, pilih opsi Dinonaktifkan. Fungsi ini banyak juga dipilih dengan alasan keamanan. Jangan lupa akhiri pengaturan menu Email \& Seluler dengan klik tombol Simpan Setelan.

10. OpenID

Di sini tidak ada yang harus di atur, melainkan pemberitahuan bahwa alamat blog anda bisa digunakan sebagai alamat opened

11. Izin

Pada menu ini anda dapat menambahkan penulis dengan cara di undang ke email yang anda anggap layak untuk ikut serta menjadi penulis di blog anda. Pada Siapa yang bisa melihat blog ini? : Anda dapat memilih siapa saja yang dapat mengakses blog anda. Opsi Siapapun berarti blog anda terbuka untuk umum atau bisa dibuka oleh siapa saja. Hanya orang-orang yang saya pilih yaitu hanya orang-orang yang di undang oleh anda yang dapat mengakses blog anda dengan cara login terlebih dahulu. Hanya penulis blog berarti hanya penulis saja yang bisa mengakses isi halaman blog anda, Opsi Hanya penulis blog terkadang di 
Available online at https://jurnal.stmikroyal.ac.id/index.php/jurdimas

gunakan juga pada saat mengganti template, agar blog anda tidak terlihat semrawut ketika mengganti template.

12. Cara mengganti template dengan template yang telah disediakan blogger.

Berikut cara-cara untuk mengganti template dengan template yang telah disediakan blogger:

- Silahkan login ke blogger dengan ID anda.

- Klik Rancangan

- Klik menu Perancang Template. Selanjutnya akan muncul jendela perancang template blogger.

- Klik pada pilihan template yang tersedia (saat tartikel ini ditulis template yang terdia berjumlah 6 template). Selain itu, anda dapat pula memilih background atau gambar latar belakang dari template tersebut. Jika sudah cocok dengan salah satu template, ke Blog.

- Selesai.

13. Mengganti template dengan template dari penyedia template.

Berikut cara-cara untuk mengganti template dengan template dari penyedia template:

- Download terlebih dahulu template yang anda sukai pada website penyedia template blog gratis. Salah satu contoh anda bisa download di blogtemplate4u.com.

- File template yang didownload, biasanya masih dalam bentuk terkompresi (zip atau rar), oleh karenanya anda perlu mengekstrak atau menguraikan file tersebut dengan software ekstraktor sperti WinZip atau WinRar.

- Yang nanti di upload atau di unggah ke blogger hanyalah file yang berekstensi .xml.

- Silahkan login ke blogger dengan
ID anda.

- Klik Rancangan

- Klik menu Edit HTML.

- Disarankan untuk membuat backup terlebih dahulu, klik pada tulisan Download Template Lengkap.

- Klik tombol Browse.., pilih file template yang tadi didownload dan telah diekstrak (file ekstensi .xml saja ). Kemudian klik tombol Unggah.

- Apabila muncul peringatan tentang widget, klik pada tombol Pertahankan Widget.

14. Cara memposting artikel

Bagi anda yang mengalami sedikit kendala tentang tata cara memposting suatu artikel kedalam blog, maka kali ini akan di bahas tentang tata cara posting di blogger.com. Di dalam menu posting ada beberapa toolbar yang bisa anda gunakan. Jika anda sudah terbiasa menggunakan microsoft Word ataupun microsoft Excel tentu barangkali tidak akan mengalami kesulitan ketika memposting suatu artikel.

15. Google Docs

Sebagai seorang guru, dosen atau lainnya sangat dibutuhkan server yang digunakan untuk mengupload file dokumen yang dimiliki baik berformat doc, pdf, xls dll untuk dapat di download bagi mahasiswa / siswa yang membutuhkannya. Salah satu fasilitas Google yang bisa kita nikmati untuk menyimpan dokumen-dokumen yang kita miliki di internet adalah dengan menggunakan google Docs. Langkah-langkahnya adalah : Silahkan kunjungi alamat docs.google.com 


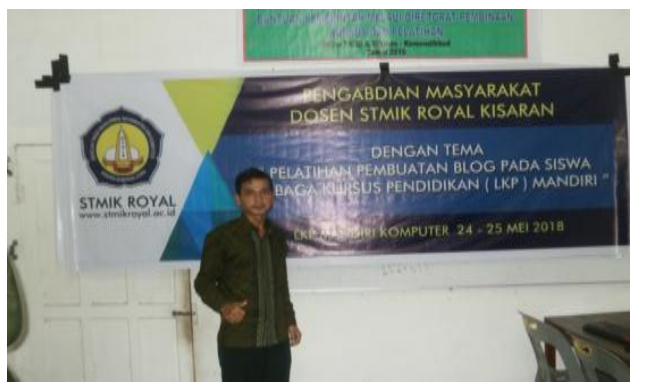

Gambar 5. Persiapan Kegiatan

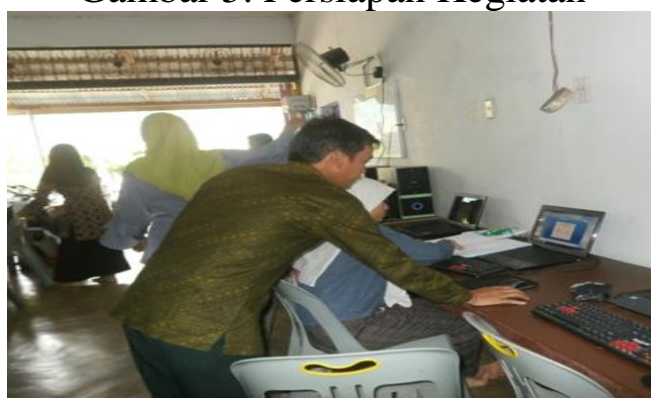

Gambar 6 Praktek Membuat Blog

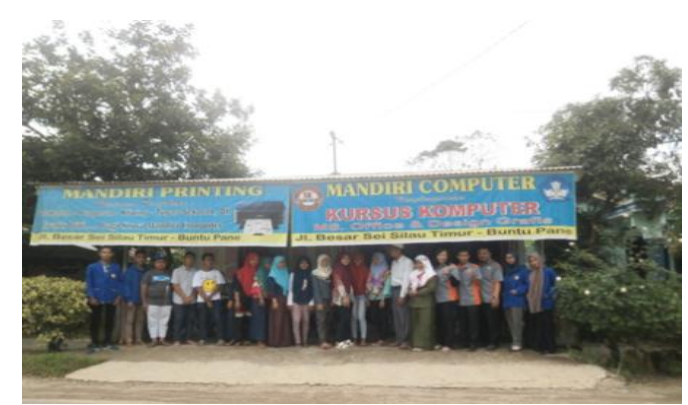

Gambar 7 Foto Bersama Para Dosen dan Siswa LKP Mandiri

\section{SIMPULAN}

Berdasarkan kegiatan pengabdian kepada masyarakat yang dilakukan pada Lembaga Kursus Pendidikan Komputer Mandiri Kecamatan Buntu Pane Kabupaten Asahan bahwa, kegiatan pengabdian kepada masyarakat yang dilakukan oleh Tim kegiatan (dosen dan mahasiswa STMIK Royal Kisaran) tepat pada sasaran. Materi kegiatan yang diberikan kepada peserta dapat digunakan dan dimanfaatkan dalam membuat blog. Materi yang disampaikan kepada peserta mencapai 90\% dari semua konsep yang ada pada pembuatan blog. Penyampaian materi terdiri dari beberapa sesi, yaitu: penjelasan, praktek, dan diskusi. Fasilitas yang disediakan oleh pimpinan Lembaga Kursus Pendidikan Mandiri Komputer sangat lengkap, mulai dari projector, in focus, microfon, kipas angin, dan lain-lain, sehingga situasi dan keadaan ruangan sangat nyaman dan aman.

Kegiatan pengabdian kepada masyarakat ini tentunya, tak terlepas dari bantuan berbagai pihak, untuk itu ucapan terima kasih kami sampaikan kepada:

1. Bapak Anda Putra Lubis, SE., MMA, Ketua Yayasan Royal Teladan Asahan, sebagai penyandang dana,

2. Bapak Pimpinan LKP Mandiri Computer beserta seluruh pegawai dan siswanya.

3. Tim pengabdian kepada masyarakat yang telah bekerjasama dengan baik, sehingga kegiatan dapat berjalan lancar dan sukses.

\section{DAFTAR PUSTAKA}

Anonim. 2012. http://office.microsoft .com/en-us/excel/. Diakses tanggal: 29 Juni 2018.

Anonim.2012.http://id.wikipedia.org/ wiki/ Microsoft_Excel. Diakses tanggal: 29 Juni 2018

Farhan Aziz Lubis. 2014.http://pangeranarti.blogspo t.com/2014/11/pengertianmicrosoft-excel-lengkap.html. Diakses tanggal: 29 Juni 2018 